\title{
Evaluating a Pharmacist-Led Opioid Stewardship Initiative at an Urban Teaching Hospital
}

\author{
Anna Chen, Michael Legal, Stephen Shalansky, Tamara Mihic, and Victoria Su
}

Can J Hosp Pharm. 2021;74(3):248-55

DOI: 10.4212/cjhp.v74i3.3152

\begin{abstract}
Background: Deaths due to overdose from illicit drugs have risen in Canada, despite various community-led harm reduction programs. There have been limited pharmacist-led inpatient initiatives aimed at reducing opioid harm. The authors' group recently developed and implemented the Medication and Risk Factor Review, Optimize, Refer at Risk Patients, Educate and Plan (MORE) tool, a systematic checklist designed to help pharmacists follow and enhance the safety of in-hospital opioid prescribing.
\end{abstract}

Objectives: To evaluate the impact of a pharmacist-led opioid stewardship program utilizing the MORE tool in the care of patients at one tertiary teaching hospital.

Methods: This study involved a review of health care records for patients admitted to general surgery and internal medicine clinical teaching units at a tertiary hospital between September 10 and December 31, 2018, for whom opioids were prescribed during the hospital stay. A descriptive data analysis was performed for patients who underwent assessment with the MORE tool.

Results: Of the 210 patients who met the initial eligibility criteria, including in-hospital opioid therapy for at least 3 days, 50 were assessed by a pharmacist using the MORE tool. For $40(80 \%)$ of these patients, the pharmacist recommended an intervention, and 35 (87.5\%) of these interventions were accepted by the prescriber. Among all 50 patients, the most common pharmacist interventions were adding or optimizing non-opioid pain medications (23 patients [46\%]), decreasing opioid dose or frequency (15 patients [30\%]), and adding a bowel regimen (9 patients [18\%]).

Conclusions: Most patients who underwent assessment by a pharmacist had risk factors for adverse events from opioid prescriptions and/or suboptimal orders and drug combinations. The MORE tool provided a guided approach for pharmacists to make targeted interventions aimed at improving opioid safety. A dedicated opioid stewardship pharmacist might be able to provide additional benefit.

Keywords: opioid-related disorders, pharmacists, stewardship, health care

\section{RÉSUMÉ}

Contexte : Les décès provoqués par les surdoses de drogues illégales ont augmenté au Canada, malgré les divers programmes communautaires axés sur la réduction des risques. Le nombre d'initiatives menées par les pharmaciens auprès des patients hospitalisés visant à réduire les dommages causés par les opioïdes est limité. Le groupe d'auteurs de cette étude a récemment élaboré et mis en place l'outil Medication and Risk Factor Review, Optimize, Refer at Risk Patients, Educate and Plan (MORE) : une liste de contrôle systématique conçue pour aider les pharmaciens à respecter et à renforcer la sécurité de la prescription d'opioïdes en milieu hospitalier.

Objectifs : Évaluer l'impact d'un programme de gestion des opioïdes dirigé par des pharmaciens à l'aide de l'outil MORE pour les soins des patients résidant dans un hôpital d'enseignement tertiaire.

Méthodes : Cette étude impliquait l'examen des dossiers de santé des patients admis dans les unités d'enseignement clinique de chirurgie générale et de médecine interne d'un hôpital tertiaire entre le 10 septembre et le 31 décembre 2018. Des opioïdes ont été prescrits à ces patients lors de leur séjour hospitalier. Une analyse descriptive des données a été menée auprès des patients ayant fait l'objet d'une évaluation à l'aide de l'outil MORE.

Résultats : Sur les 210 patients qui répondaient aux critères d'admissibilité initiaux, notamment à celui d'un traitement aux opioïdes à I'hôpital pendant au moins trois jours, 50 ont fait l'objet d'une évaluation à l'aide de l'outil MORE. Le pharmacien a recommandé une intervention auprès de 40 de ces patients (80\%), et le prescripteur a accepté 35 de ces interventions (87,5\%). Les interventions des pharmaciens les plus répandues réalisées auprès des 50 patients consistaient en l'ajout ou en I'optimisation des analgésiques sans opioïdes (23 patients [46 \%]); en la diminution de la dose d'opioïdes ou de leur fréquence (15 patients [30\%]); et en l'ajout d'un régime d'hygiène intestinale (9 patients [18 \%]).

Conclusions : La plupart des patients ayant fait l'objet d'une évaluation menée par un pharmacien présentaient des facteurs de risque d'effets indésirables découlant des prescriptions d'opioïdes et/ou d'ordonnances et de combinaisons médicamenteuses sous-optimales. L'outil MORE a permis aux pharmaciens d'adopter une approche guidée pour qu'ils puissent effectuer des interventions ciblées visant à améliorer l'innocuité des opioïdes. Un pharmacien affecté spécifiquement à la gestion des opioïdes pourrait offrir des avantages supplémentaires.

Mots-clés : troubles liés aux opioïdes, pharmaciens, gestion, soins de santé 


\section{INTRODUCTION}

Deaths due to illicit drug overdose have steadily increased in Canada in the past few years. ${ }^{1}$ In British Columbia, 1550 people died from a preventable overdose in 2018, 985 in 2019 , and an additional 1723 in $2020 .^{2}$ The tragic number of deaths and overdoses due to opioid use led to the declaration of a public health emergency in April 2016. ${ }^{3}$ Various measures have been implemented to address this public health emergency, but few interventions have addressed the role of prescription opioids. Research indicates that individuals who experienced an overdose were more likely to have had an opioid prescription for pain and were more likely to have used prescription opioids on a long-term basis (typically for more than 3 months) over the previous 5 years, relative to people who did not experience an overdose. ${ }^{4}$ In addition, chronic opioid use at 1 year after hospital discharge is more common among opioid-naive patients for whom an opioid was prescribed at discharge than among patients who did not receive opioids in the hospital. ${ }^{5}$ These results suggest a potential need for in-hospital pharmacist interventions, such as opioid stewardship, to address prescribing patterns that affect this public health emergency.

Opioid stewardship is defined as the implementation of coordinated interventions to improve, monitor, and evaluate the use of opioids to support and protect the people using these drugs. ${ }^{6}$ The goal of an opioid stewardship program is to ensure optimal analgesic prescribing, using opioid and non-opioid alternatives, to reduce the risk of adverse events and to avoid the development of opioid use disorder in patients and/or their family and acquaintances. Opioid stewardship should not be considered an attempt to stop necessary and appropriate opioid therapy for patients for whom other options have been tried without success, or those with indications for which opioids have proven benefit. Rather, opioid stewardship attempts to ensure that opioids are used in a safe and rational manner.

Recent research regarding opioid stewardship programs has included an assessment of a pharmacist-led pain service in a community hospital setting, which showed a reduction in opioid use, an increase in use of co-analgesic medications, such as acetaminophen and nonsteroidal anti-inflammatory drugs, and an overall increase in patient satisfaction. ${ }^{7}$ Another pharmacist-led opioid stewardship program implemented in a Canadian primary care centre showed an increase in opioid tapering and a decrease in overall opioid doses. ${ }^{8}$

We conducted this study at St Paul's Hospital, a 430-bed tertiary teaching hospital located in a community of Vancouver, British Columbia, that is heavily affected by the opioid crisis. At this hospital, the Addictions Medicine Consult Team, the Acute Pain Service, and the Chronic Pain Service oversee opioid therapy for specific subsets of patients by consultation. Opioid use by the rest of the hospital's patient population receives less focused attention. In an effort to target opioid prescribing in the broader hospital population, our team developed the MORE tool. The MORE Clinical Pharmacist Opioid Review and Optimization Tool gets its name from an acronym based on the following concepts: Medication and Risk Factor Review, Optimize, Refer at Risk Patients, Educate and Plan. It was created in response to the need for a pharmacist-led opioid stewardship initiative based on best practices from the literature and feedback from local pharmacist focus groups. ${ }^{9}$ This clinical tool provides a systematic checklist for pharmacists to follow to enhance the safety of opioid prescribing while ensuring effective pain management. ${ }^{9}$ The latest version of the tool is available in Appendix 1 (see https://www.cjhp-online.ca/ index.php/cjhp/issue/view/205.) Details about the development of this tool were published previously. ${ }^{9}$

The MORE tool was implemented for use by hospital pharmacists working on general medical and surgical units at the study hospital in August 2018. As specified in the tool itself, the MORE tool was intended for use in the assessment of patients with noncancer pain. For initial implementation, as evaluated here, the tool was not applied in the emergency department, critical care units, or other specialty units. If the initial roll-out is deemed successful, expansion to other areas of the hospital will be considered. For further details on how pharmacists can use the MORE tool, please refer to our previous work. ${ }^{9}$

The aim of the current study was to evaluate the impact of our hospital's pharmacist-led opioid stewardship program utilizing the MORE tool.

\section{METHODS}

\section{Design}

This study involved a retrospective review of health care records for patients admitted to general surgery and internal medicine clinical teaching units at the tertiary hospital between September 10 and December 31, 2018, for whom opioids were prescribed during the hospital stay. The pharmacist-driven MORE tool had been implemented in August 2018, before the current study began.

\section{Patient Population}

The baseline population was identified using the pharmacy computer system, which listed all adult patients $(\geq 19$ years of age) admitted to an internal medicine clinical teaching unit or general surgery ward at the tertiary hospital who received at least 1 prescription for either regularly scheduled or "as-needed" opioid therapy for a duration of 3 days or longer. Patients who were being actively followed by the Addictions Medicine Consult Team or one of the pain services before the MORE tool became available were excluded from the baseline population. In addition, patients were excluded if their only opioid prescription was for opioid 
agonist treatment for opioid use disorder (e.g., methadone or buprenorphine-naloxone). The opioid stewardship cohort consisted of patients in the baseline population who underwent assessment with the MORE tool. Completed and partially completed MORE assessments were routinely collected, along with other pharmacy documentation materials, when patients were discharged.

\section{Sample Size}

A convenience sample was chosen that included all patients who were admitted during the 4-month study period and who met the inclusion criteria. From this group, detailed chart review was conducted for patients for whom a MORE assessment was completed. It was felt that this time frame would be adequate to indicate the impact of the tool in guiding pharmacist-led opioid stewardship during the early implementation phase.

\section{Outcomes}

The primary outcome measures were the proportion of patients in the baseline population who were assessed by a clinical pharmacist using the MORE tool (thus forming the opioid stewardship cohort) and the proportion of patients in the opioid stewardship cohort for whom an opioid stewardship intervention suggested by a pharmacist was documented in the MORE tool.

The secondary outcome measures included mean numbers (per patient) of suboptimal orders, risk factors for opioid-related adverse events, and opioid stewardship interventions (actions) among medical patients relative to surgical patients. Other secondary outcome measures included the proportions of pharmacist-recommended interventions that were accepted or implemented, pharmacist-recommended interventions that were documented in the health record, and patients who experienced any chart-documented, opioidrelated adverse event.

\section{Data Collection}

For the baseline population, data collection was limited to the elements needed to determine whether the patient met the inclusion criteria. For the opioid stewardship cohort, the following demographic and baseline clinical characteristics were collected from the patient chart: age, sex, ward of admission, reason for admission, comorbidities, opioid medications before admission, substance use history as documented in the patient history, and in-hospital medications, specifically opioids ordered (regimen and total daily dose, as morphine milligram equivalents [MME] per day), concurrent non-opioid analgesics (dose and regimen), and documentation of any changes in the opioid regimen. Documentation of pain management and opioid prescribing interventions, either suggested by the pharmacist or implemented by other health care providers, was also recorded.
Comorbidities were extracted from the past medical history in the electronic chart. Regular opioid use before admission and median daily MME used in hospital were gathered from the MORE assessment and confirmed via review of the patient chart.

\section{Statistical Analysis}

Descriptive statistics were used to analyze the data, and the results are reported using means, medians, and proportions.

The research protocol was submitted to the Providence Health Research Ethics Board and approved before the commencement of data collection.

\section{RESULTS}

Assessment with the MORE tool was completed for a total of 50 patients admitted during the defined study period, 30 on medicine units and 20 on surgery units; A total of 5 pharmacists performed these assessments, all of them residency trained, with a range of 1 to 10 years of experience.

The baseline characteristics of patients in the opioid stewardship cohort are reported in Table 1. Patients assessed by clinical pharmacists with the MORE tool tended to be elderly (mean age 69.1 years), and 33 (66\%) were female. A third of patients had prescriptions for regularly scheduled opioids before admission, and a similar proportion had a comorbid psychiatric diagnosis such as anxiety or depression. In hospital, hydromorphone was the most commonly prescribed opioid, representing $85 \%$ of all opioid orders.

\section{Primary Outcome Measures}

A study flow diagram of patients in the baseline population and the opioid stewardship cohort is presented in Figure 1. The clinical pharmacists used the MORE tool to assess $24 \%(50 / 210)$ of eligible patients receiving opioids (baseline population) who were admitted during the study period.

Of the 50 patients assessed with the MORE tool (the opioid stewardship cohort), pharmacists suggested interventions for $40(80 \%)$.

\section{Secondary Outcome Measures}

Among the 50 patients in the opioid stewardship cohort, there were 52 suboptimal medication orders or medication combinations, yielding a mean of 1.04 suboptimal orders per patient. The most frequent problems with suboptimal orders were suboptimal dose, route, or frequency of opioids; lack of optimized non-opioid pain medications; and duplicate opioid orders. The breakdown of the various suboptimal orders is presented in Table 2.

A total of 79 risk factors for adverse events were found in the opioid stewardship cohort, for a mean of 1.58 per patient. The most common risk factors were age older than 75 years, kidney or liver impairment, and a history of substance use disorder. The breakdown of these risk factors is presented in Table 3. 


\begin{tabular}{|c|c|c|c|c|c|c|}
\hline \multirow{4}{*}{$\begin{array}{l}\text { Characteristic } \\
\text { Mean age (years) } \\
\text { Sex, female }\end{array}$} & \multicolumn{6}{|c|}{ Service; No. (\%) of Patients ${ }^{a}$} \\
\hline & \multicolumn{2}{|c|}{$\begin{array}{c}\text { Medicine } \\
(n=30)\end{array}$} & \multicolumn{2}{|c|}{$\begin{array}{l}\text { Surgery } \\
(n=20)\end{array}$} & \multicolumn{2}{|c|}{$\begin{array}{l}\text { All Patients } \\
\quad(n=50)\end{array}$} \\
\hline & \multicolumn{2}{|c|}{71.6} & \multicolumn{2}{|c|}{65.5} & \multicolumn{2}{|c|}{69.1} \\
\hline & 21 & $(70)$ & 12 & $(60)$ & 33 & (66) \\
\hline \multicolumn{7}{|l|}{ Comorbidities } \\
\hline Atrial fibrillation & 4 & (13) & 3 & $(15)$ & 7 & (14) \\
\hline Coronary artery disease & 5 & $(17)$ & 3 & $(15)$ & 8 & (16) \\
\hline Chronic pain & 5 & $(17)$ & 0 & $(0)$ & 5 & $(10)$ \\
\hline Chronic obstructive pulmonary disease & 7 & $(23)$ & 1 & (5) & 8 & (16) \\
\hline Depression & 7 & $(23)$ & 1 & (5) & 8 & (16) \\
\hline Diabetes & 7 & $(23)$ & 3 & $(15)$ & 10 & (20) \\
\hline Dyslipidemia & 6 & $(20)$ & 4 & $(20)$ & 10 & (20) \\
\hline Hypertension & 16 & (53) & 10 & $(50)$ & 26 & (52) \\
\hline Hypothyroidism & 3 & $(10)$ & 3 & $(15)$ & 6 & $(12)$ \\
\hline Osteoarthritis & 5 & (17) & 2 & $(10)$ & 7 & (14) \\
\hline Osteoporosis & 6 & $(20)$ & 0 & (0) & 6 & $(12)$ \\
\hline Smoking history & 3 & $(10)$ & 2 & $(10)$ & 5 & (10) \\
\hline History of substance use disorder ${ }^{b}$ & 5 & $(17)$ & 4 & $(20)$ & 9 & $(18)$ \\
\hline Psychiatric diagnosis & 9 & (30) & 8 & $(40)$ & 17 & (34) \\
\hline Receiving regularly scheduled opioids before admission & 11 & $(37)$ & 5 & $(25)$ & 16 & $(32)$ \\
\hline Opioids on medication administration record on day of discharge & 24 & $(80)$ & 15 & $(75)$ & 39 & (78) \\
\hline \multicolumn{7}{|l|}{ Proportion of hospital stay (measured in days) with opioid therapy } \\
\hline Mean $\%$ of hospital stay with as-needed opioid therapy & \multicolumn{2}{|c|}{85.7} & \multicolumn{2}{|c|}{86.6} & \multicolumn{2}{|c|}{86.1} \\
\hline Mean $\%$ of hospital stay with scheduled opioid therapy & \multicolumn{2}{|c|}{61.7} & \multicolumn{2}{|c|}{41.2} & \multicolumn{2}{|c|}{54.2} \\
\hline \multicolumn{7}{|l|}{ Median daily $\mathrm{MME}^{\mathrm{C}}$ received } \\
\hline Total (as needed and/or regular) & \multicolumn{2}{|c|}{20} & \multicolumn{2}{|c|}{27.5} & \multicolumn{2}{|c|}{20} \\
\hline Regular & \multicolumn{2}{|c|}{35.3} & \multicolumn{2}{|c|}{20} & \multicolumn{2}{|c|}{30} \\
\hline
\end{tabular}

${ }^{a}$ Except where indicated otherwise.

bSubstance use disorder includes alcohol use disorder and polysubstance abuse.

'Morphine milligram equivalents, based on opioids ordered and used, as reported in the pharmacy system.

The pharmacists suggested a total of 62 optimization interventions. The most common interventions were adjusting the dose or frequency of opioids and optimizing or adding non-opioid pain medications (such as acetaminophen). The mean number of optimization interventions per patient was 1.24. The mean number of optimization interventions per medicine patient was 1.47 , whereas the mean per surgical patient was 0.9 . Of the 40 patients with an intervention suggested by the pharmacist, 35 (87.5\%) had the interventions accepted by the care team. Among all 50 patients in the opioid stewardship cohort, 17 (34\%) had a note related to their opioids or pain management in the progress notes section of the patient chart. The breakdown of the various pharmacist interventions is presented in Table 4.

The pharmacists suggested a total of 6 referrals to other services, specifically the Addictions Medicine Consult Team, the Acute Pain Service, the Chronic Pain Service, and the palliative care team.
A total of 55 education or planning interventions were suggested (mean 1.1 interventions per patient). These interventions involved 22 of the 50 patients in the opioid stewardship cohort, which indicates that patients with education or planning interventions typically had multiple interventions of this type. The mean numbers of education interventions by service type were 1.23 per patient in the medicine units and 0.9 per patient in the surgical units. The most common educational interventions were discussion of pain goals (14 patients [28\%]), counselling about non-opioid options (13 patients [26\%]), and recommendation to taper or discontinue opioids (12 patients [24\%]). The breakdown of the various education and planning interventions is shown in Table 5.

Five (10\%) of the patients in the opioid stewardship cohort had a chart-documented adverse event, 2 with sedation and 3 with "other" adverse events (hallucinations and dizziness, nausea, or opioid withdrawal). 


\section{DISCUSSION}

In this study, clinical pharmacists selected the patients who would undergo assessment using the MORE tool as a guide. It is likely that the pharmacists used their clinical judgment

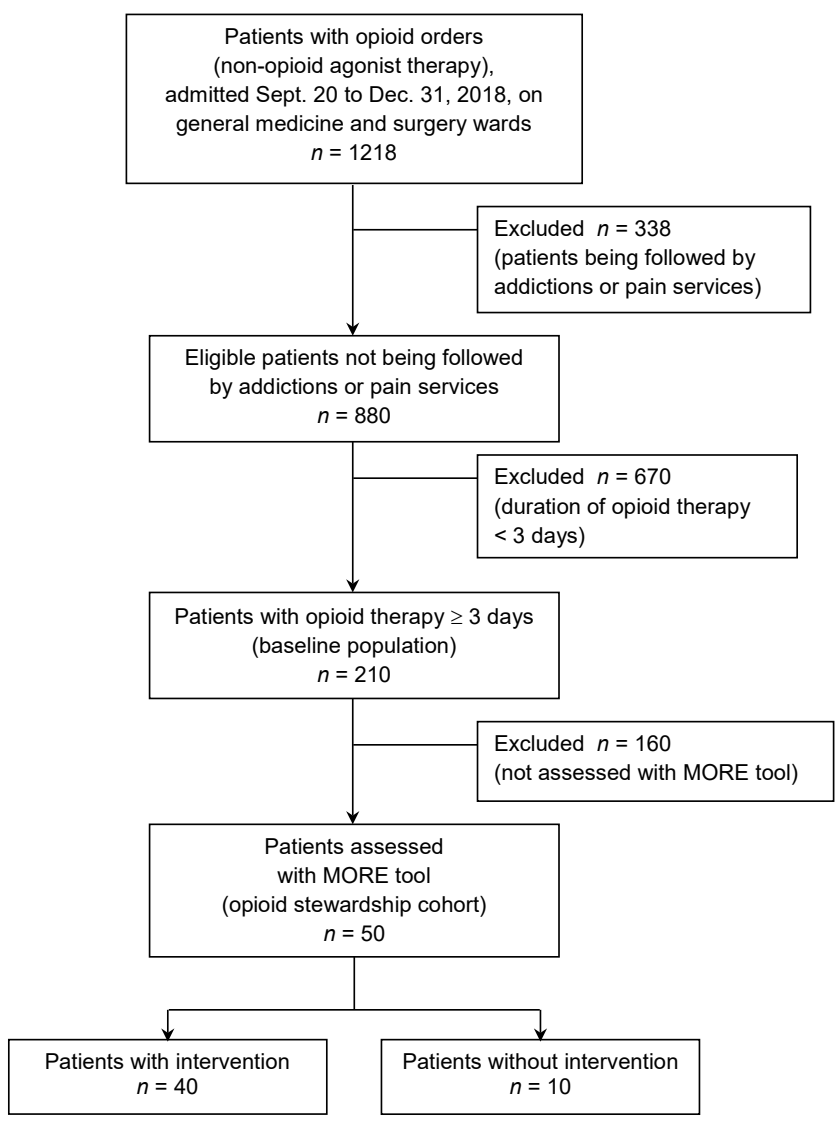

FIGURE 1. Study flow diagram. to preferentially select patients with readily apparent risk factors or suboptimal analgesic orders. Overall, the patients selected for assessment were older and more predominately female, and many had medical comorbidities such as hypertension, diabetes, or psychiatric comorbidities. Interestingly, this population contrasts with literature reports of those most at risk for opioid use disorder, specifically men aged 50 years or older. ${ }^{10}$ It is possible that the more typical at-risk population described in the literature is preferentially assessed and followed by specialty addiction or pain services at the study hospital. As such, the group targeted by pharmacists in the current study may represent an under-recognized at-risk population.

The pharmacists were able to apply the tool in $24 \%$ of the patients for whom in-hospital use of opioids was prescribed for more than 3 days. Although this proportion may seem low, it is important to highlight that these patients were not concurrently under the care of physicians with specialized training in pain or addiction management. Instead, they represent the larger population of hospitalized patients who receive opioids without review by medical experts in pain or addiction. Also, the clinical pharmacists added assessment using the MORE tool to their existing workload and were not given additional dedicated time for this activity. Assessment of this under-recognized population by the pharmacy team, despite limited resources for doing so, suggests that clinical pharmacists can have an important role in opioid stewardship. It also suggests that there may be value in having a dedicated opioid stewardship team, similar to the antimicrobial stewardship model, since there remains a substantial proportion of patients who are receiving opioids but are not being formally assessed for risk. The activities of a dedicated opioid stewardship team could

TABLE 2. Suboptimal Medication Orders and Drug Combinations

Service; No. (\%) of Patients

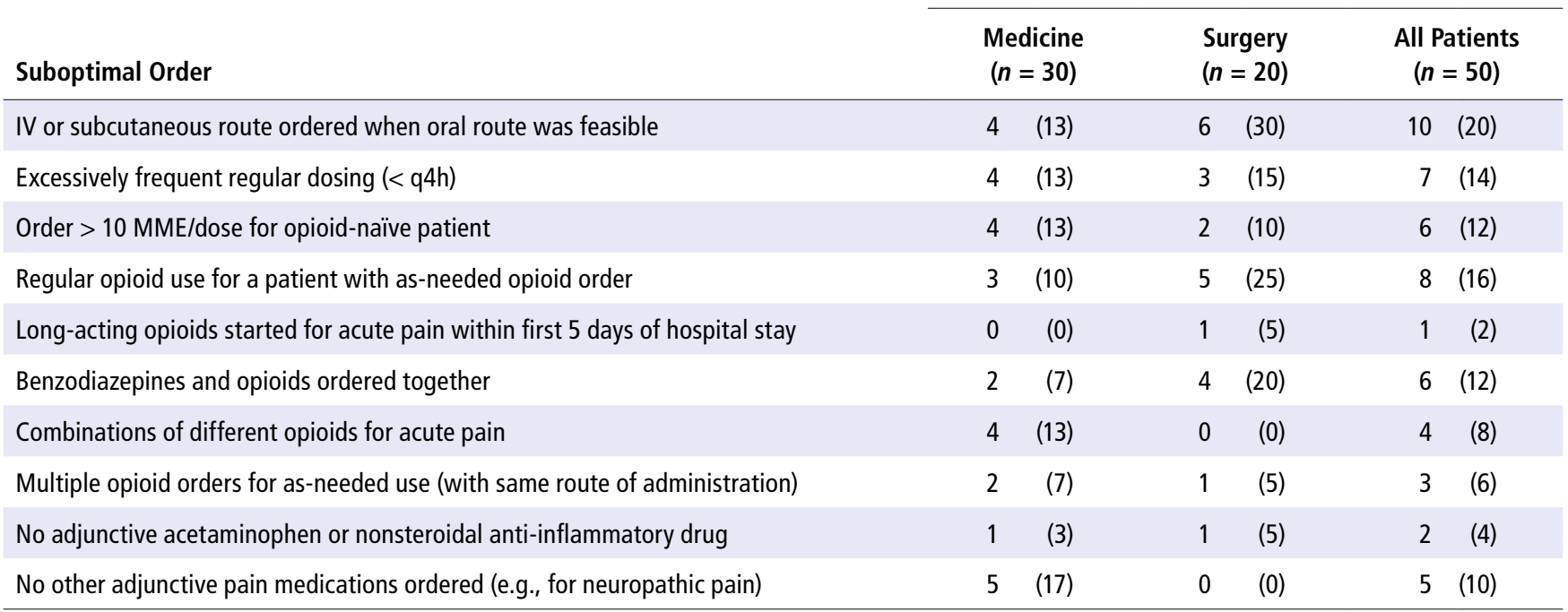

$\mathrm{MME}=$ morphine milligram equivalents 
include conducting in-depth patient interviews, reviewing past and current pain therapies, identifying non-opioid analgesic combinations to be added to current therapy, and educating other health care professionals about updated guidelines and evidence for use of opioids.

At the time of our study, there was limited published information on pharmacist-led opioid stewardship interventions; however, since our study was completed, several reports describing pharmacist-led opioid stewardship programs have been published. One report described implementation of a pharmacy-directed pain management service. ${ }^{7}$ This pharmacy consult-based pain management service aimed to achieve optimal pain management, reduce adverse events associated with pain medications, and reduce the use of higher-risk pain medications. ${ }^{7}$ The authors showed decreased use of high-risk opioid medications, such as parenteral hydromorphone and fentanyl, and increased use of co-analgesics, including acetaminophen and nonsteroidal anti-inflammatory drugs such as ibuprofen and naproxen. ${ }^{7}$ That study differed from ours, in that it was a consult-based service with dedicated clinical pharmacists. In another study, conducted in a primary care setting, the pharmacist at the intervention primary care clinic reviewed patient charts for opioid prescribing, communicated with clinic physicians, and offered suggestions for opioid tapering. ${ }^{8}$ In that study, there was a reduction in mean daily

\section{TABLE 3. Risk Factors for Adverse Events due to Opioids}

\begin{tabular}{|c|c|c|c|}
\hline \multirow{3}{*}{$\begin{array}{l}\text { Risk Factor } \\
\text { Age }>75 \text { years }\end{array}$} & \multicolumn{3}{|c|}{ Service; No. (\%) of Patients } \\
\hline & $\begin{array}{l}\text { Medicine } \\
(n=30)\end{array}$ & $\begin{array}{l}\text { Surgery } \\
(n=20)\end{array}$ & $\begin{array}{l}\text { All Patients } \\
\quad(n=50)\end{array}$ \\
\hline & $13(43)$ & $3(15)$ & $16 \quad(32)$ \\
\hline Family history of substance use disorder & $0 \quad(0)$ & $1 \quad(5)$ & $1 \quad(2)$ \\
\hline Any history of substance use disorder & $5 \quad(17)$ & $4 \quad(20)$ & 9 (18) \\
\hline Kidney or liver impairment & $5 \quad(17)$ & $5 \quad(25)$ & $10(20)$ \\
\hline Low body mass index & $5 \quad(17)$ & $3(15)$ & $8 \quad(16)$ \\
\hline Multiple overlapping fills of opioids documented in PharmaNet prescription database & (7) & $(0)$ & (4) \\
\hline Multiple prescribers for opioids documented in PharmaNet prescription database & (3) & $(0)$ & $1 \quad(2)$ \\
\hline Opioid dose rapidly increased in recent days or weeks & $1 \quad(3)$ & $4 \quad(20)$ & $5 \quad(10)$ \\
\hline Psychiatric diagnosis & $9 \quad(30)$ & $8 \quad(40)$ & $17 \quad(34)$ \\
\hline Receiving $>50$ MME of opioid daily (but $<100 \mathrm{MME})^{\text {a }}$ & $3 \quad(10)$ & (5) & $4 \quad(8)$ \\
\hline Receiving $>100$ MME of opioid daily ${ }^{a}$ & $5 \quad(17)$ & (5) & $6 \quad(12)$ \\
\hline
\end{tabular}

${ }^{\mathrm{a}} \mathrm{MME}=$ morphine milligram equivalents, based on opioids received according to medication administration records in hospital.

\section{TABLE 4. Pharmacist Optimization Interventions}

Service; No. (\%) of Patients

\begin{tabular}{|c|c|c|c|c|c|c|}
\hline \multirow{2}{*}{$\begin{array}{l}\text { Intervention } \\
\text { Add bowel regimen }\end{array}$} & \multicolumn{2}{|c|}{$\begin{array}{c}\text { Medicine } \\
(n=30)\end{array}$} & \multicolumn{2}{|c|}{$\begin{array}{l}\text { Surgery } \\
(n=20)\end{array}$} & \multicolumn{2}{|c|}{$\begin{array}{l}\text { All Patients } \\
\quad(n=50)\end{array}$} \\
\hline & 9 & $(30)$ & 0 & $(0)$ & 9 & $(18)$ \\
\hline Add non-opioid pain medication ${ }^{a}$ & 7 & $(23)$ & 4 & $(20)$ & 11 & $(22)$ \\
\hline Optimize non-opioid pain medication & 10 & (33) & 2 & $(10)$ & 12 & (24) \\
\hline Decrease opioid dose or frequency & 9 & $(30)$ & 6 & (30) & 15 & $(30)$ \\
\hline Change intravenous or subcutaneous to oral route & 3 & $(10)$ & 3 & $(15)$ & 6 & $(12)$ \\
\hline Deprescribe as-needed opioid & 3 & $(10)$ & 0 & $(0)$ & 3 & (6) \\
\hline Deprescribe regularly scheduled opioid & 1 & (3) & 2 & $(10)$ & 3 & (6) \\
\hline Switch to different opioid & 2 & (7) & 1 & (5) & 3 & (6) \\
\hline
\end{tabular}

${ }^{a}$ Acetaminophen, gabapentin, and/or nonsteroidal anti-inflammatory drug. 


\begin{tabular}{|c|c|c|c|c|}
\hline \multirow{3}{*}{$\begin{array}{l}\text { Intervention } \\
\text { Chart documentation about education or planning intervention }\end{array}$} & \multicolumn{4}{|c|}{ Service; No. (\%) of Patients } \\
\hline & $\begin{array}{l}\text { Medicine } \\
(n=30)\end{array}$ & $\begin{array}{l}\text { Surgery } \\
(n=20)\end{array}$ & \multicolumn{2}{|c|}{$\begin{array}{l}\text { All Patients } \\
\qquad(n=50)\end{array}$} \\
\hline & $1 \quad(3)$ & $4 \quad(20)$ & 5 & $(10)$ \\
\hline Counsel on non-opioid options & $9 \quad(30)$ & $4 \quad(20)$ & 13 & $(26)$ \\
\hline Counsel on proper use and disposal of excess supply & $2 \quad(7)$ & $2 \quad(10)$ & 4 & (8) \\
\hline Discuss pain goals & $8 \quad(27)$ & $6 \quad(30)$ & 14 & $(28)$ \\
\hline Pain/opioid plan communicated to community health care providers & $1 \quad(3)$ & $(0)$ & 1 & (2) \\
\hline Recommend appropriate duration/quantity & $6 \quad(20)$ & $(0)$ & 6 & $(12)$ \\
\hline Recommend opioid taper or discontinuation & $10 \quad(33)$ & $2(10)$ & 12 & (24) \\
\hline
\end{tabular}

opioid doses over a 4 -month period. ${ }^{8}$ The pharmacist in that study added review of patients' electronic charts for opioid prescribing to their existing workload (similar to what was required of the pharmacists in our study), rather than having a consult-based analgesic review. The main difference between this second study and ours was the setting: our study took place in a tertiary hospital, where the caseload of each pharmacist and patients' acuity may differ from those in a primary care centre.

The current study also demonstrates that risk factors for opioid-related adverse events, such as advanced age, impaired organ function, and prior psychiatric history or substance use history, are common in the general medical and general surgical populations. Most of the patients assessed in this study had at least 1 suboptimal opioid or co-analgesic order. One-third of the patients were receiving opioids before admission, despite having risk factors for adverse effects or development of an opioid use disorder. It is also concerning that on the day of discharge, most of the medical patients $(80 \%)$ still had opioids on their medication administration record, despite only $37 \%$ of them having had opioid prescriptions before hospital admission. This can likely be explained by the fact that for many patients, opioids are prescribed on an as-needed (PRN) basis during their hospital stay and although they may not need any doses, the orders remain on their medication profile until discharge. In our study, patients had orders for as-needed administration of opioids for $86.1 \%$ of their hospital stay, with orders for regularly scheduled opioids for only $54.2 \%$ of their stay. It was not clear how many patients still required PRN doses on the day of discharge; however, given the link between prescribing opioids at the time of hospital discharge and the increased risk of prolonged opioid use, earlier or more frequent reassessment of the need for ongoing opioid therapy (including PRN orders) is warranted. In addition, if the patient continues to have high opioid requirements at the time of discharge, there is a need to address the risk of opioid withdrawal symptoms on discharge and the potential need for opioid tapering.

The pharmacists suggested various interventions to optimize opioid prescribing and mitigate the risk of adverse events. One of the most common interventions was a simple one: adding a non-opioid co-analgesic. The pharmacists often added regularly scheduled non-opioid medications, even when they did not initially mark this option within the suboptimal orders section of the MORE tool. The pharmacists suggested more interventions for medicine patients than for surgical patients. Some experts have proposed that opioid stewardship interventions should be focused on surgical patients ${ }^{10}$; however, our study suggests that the risk for opioid-related adverse effects is at least as high, if not higher, for medical patients as it is for surgical patients, which resulted in a greater number of pharmacist interventions for this group (means 1.47 and 0.9 per patient, respectively, in the opioid stewardship cohort). Despite the relatively high frequency of suggested interventions, the number of chart notes documenting pharmacist interventions was low. We assumed that most pharmacist interventions in this study resulted in collaborative discussion with the care teams instead of a chart note.

In interpreting the results of this study, it is important to note that professional judgment was involved in the selection of the opioid stewardship cohort. As a result, the frequency of risk factors and the need for interventions might have been higher in the opioid stewardship cohort than in the general hospital population. Because we did not review the charts of patients who were not assessed by pharmacists using the MORE tool, we cannot draw conclusions about the frequency of risk factors in that population. The types of interventions might have been influenced by individual pharmacists and their comfort level in intervening in opioid prescribing. Furthermore, we did not assess the clinical validity of the interventions or whether potentially beneficial interventions were omitted. Initial implementation 
of the tool was limited to general medical and surgical patients needing treatment for noncancer pain, and the results of this study cannot be extrapolated to other patient populations, such as those receiving critical care or in the emergency department.

Anecdotally, the pharmacists' use of the MORE tool declined after initial implementation. The pharmacists reported that they found the tool useful but time-consuming, and we suspect that this added workload was the reason for decline in its utilization over time. Nonetheless, we found that with the aid of the MORE tool, clinical pharmacists were able to provide opioid stewardship to 50 of 210 patients, with 40 of these receiving pharmacist interventions and recommendations. The results of this study may be generalized to other hospital pharmacy departments, where a formalized checklist may help to guide opioid stewardship within pharmacists' day-to-day routine.

\section{CONCLUSION}

This study demonstrated the existence of many hospitalized patients who are not formally assessed for opioid stewardship interventions but who could benefit from such interventions. Most patients assessed by pharmacists in this study had risk factors for overdose and/or suboptimal orders and drug combinations. With the aid of a clinical tool, pharmacists were able to identify and address a variety of issues, such as suboptimal medication orders, drug combinations, and risk factors for adverse reactions, and were able to optimize therapy and provide patient education. Despite these positive interventions, it may be difficult for clinical pharmacists to add comprehensive opioid stewardship activities to their current activities. For this reason, a dedicated opioid stewardship pharmacist or team might be a worthwhile addition to clinical care.

\section{References}

1. Distribution of illicit overdose deaths (2010-2019). BC Centre for Disease Control; 2019 [cited 2019 Aug 27]. Available from: http://www .bccdc.ca/resource-gallery/Documents/Statistics\%20and\%20Research/ Statistics\%20and\%20Reports/Overdose/Illicit\%20Drug\%20Overdose \%20Deaths\%20by\%20LHA\%20BC\%20-\%20No\%20Counts.pdf

2. Illicit drug overdose deaths in BC, January 1, 2011 - March 31, 2021. BC Coroners Service; 2021 [cited 2021 May 20]. Available from: https: //www2.gov.bc.ca/assets/gov/birth-adoption-death-marriage-and -divorce/deaths/coroners-service/statistical/illicit-drug.pdf
3. Public health emergency in BC [news release]. BC Centre for Disease Control; 2017 [cited 2019 Aug 27]. Available from: http://www.bccdc. $\mathrm{ca} / \mathrm{about} /$ news-stories/stories/public-health-emergency-in-bc

4. BCCDC public knowledge summary: analyzing prescription drug histories among people who overdose. BC Centre for Disease Control; 2018 [cited 2019 Aug 27]. Available from: http://www.bccdc.ca/resource -gallery/Documents/Educational\%20Materials/Epid/Other/20180221_ BCCDC\%20Public\%20Knowledge\%20Summary_Analyzing\%20 prescription.pdf

5. Calcaterra S, Yamashita T, Min S, Keniston A, Frank J, Binswanger I. Opioid prescribing at hospital discharge contributes to chronic opioid use. J Gen Intern Med. 2016;31(5):478-85.

6. Opioid stewardship [online resources]. Institute for Safe Medication Practices Canada; 2018 [cited 2018 Jul 20]. Available from: https:// www.ismp-canada.org/opioid_stewardship/

7. Poirier R, Brown C, Baggenstos Y, Walden S, Gann N, Patty C, et al. Impact of a pharmacist-directed pain management service on inpatient opioid use, pain control, and patient safety. Am J Health Syst Pharm. 2019;76(1):17-25.

8. Tilli T, Hunchuck J, Dewhurst N, Kiran T. Opioid stewardship: implementing a proactive, pharmacist-led intervention for patients coprescribed opioids and benzodiazepines at an urban academic primary care centre. BMJ Open Qual. 2020;9(2):e000635.

9. Woods B, Legal M, Shalansky, S, Mihic T, Ma W. Designing a pharmacist opioid safety and intervention tool. Can J Hosp Pharm. 2020; 73(1):7-12.

10. Burcher KM, Suprun A, Smith A. Risk factors for opioid use disorders in adult postsurgical patients. Cureus. 2018;10(5):e2611

Anna Chen, BScPharm, ACPR, is with Lower Mainland Pharmacy Services, Royal Columbian Hospital, New Westminster, British Columbia.

Michael Legal, BScPharm, PharmD, ACPR, FCSHP, is with Lower Mainland Pharmacy Services, Vancouver, British Columbia.

Stephen Shalansky, BScPharm, PharmD, ACPR, FCSHP, is with Lower Mainland Pharmacy Services, Providence Health Care, Vancouver, British Columbia.

Tamara Mihic, BScPharm, PharmD, ACPR, is with Lower Mainland Pharmacy Services, St Paul's Hospital, Vancouver, British Columbia.

Victoria Su, BScPharm, ACPR, PharmD, is with Lower Mainland Pharmacy Services, Providence Health Care, Vancouver, British Columbia.

Competing interests: For activities unrelated to the study reported here, Tamara Mihic has received a grant from Janssen Pharmaceuticals. No other competing interests were declared.

Disclaimer: Stephen Shalansky is the Editor of the Canadian Journal of Hospital Pharmacy. He was not involved in the editorial decision-making process for this article.

Address correspondence to:

Dr Michael Legal

St Paul's Hospital

1081 Burrard Street

Vancouver BC V6Z 1Y6

email: mlegal@providencehealth.bc.ca

Funding: None received. 